\title{
OS ESTUDOS SOBRE AS MULHERES NO LAZER NOS PERIÓDICOS LICERE E RBEL
}

Recebido em: $31 / 12 / 2020$

Aprovado em: 14/02/2021

Licença:@) (1) @

Julia Drumond Cunhal

Verônica Toledo Ferreira de Carvalho ${ }^{2}$

Universidade Federal de Minas Gerais (UFMG)

Belo Horizonte $-\mathrm{MG}-$ Brasil

RESUMO: A mulher, inserida em realidades patriarcais e machistas, acaba por sofrer sistemas de opressão que influenciam as mais diversas áreas da vida, inclusive em seu lazer. Diante disso, temos como principal objetivo realizar uma revisão bibliográfica sistematizada, que visa compreender o que foi produzido em relação às mulheres nos dois periódicos vinculados aos Estudos do Lazer, as revistas Licere e Rbel. Dessa forma, analisamos as pesquisas encontradas e discutimos a possibilidade de novos horizontes sobre o assunto. Por meio de levantamento de dados, foi possível concluir que a cada ano existem mais pesquisadoras e pesquisadores interessados em discutir e compreender o lazer das mulheres, mas ainda existem lacunas a serem preenchidas.

PALAVRAS-CHAVE: Atividades de Lazer. Mulheres. Gênero. Feminilidade.

\section{THE STUDIES OF WOMEN IN LEISURE IN THE PERIODICALS LICERE AND RBEL}

ABSTRACT: The woman, inserted in patriarchal and sexist realities, ends up suffering systems of oppression that influence the most diverse areas of life, including in her leisure. Some of the studies published in periodicals such as the magazine Licere and RBEL, aim to research women's leisure or its relations with gender issues. Therefore, our objective is to carry out a systematic bibliographic review, to understand what has been published in relation to women linked to Leisure Studies. In this way, we analyze the research found and discuss the possibility of new horizons on the subject. It was possible to conclude that each year there are more investigations related to discussing and understanding women's leisure, but there are still gaps to be filled.

KEYWORDS: Leisure Activities. Women. Gender. Femininity.

\footnotetext{
${ }^{1}$ Mestre pelo Programa de Pós-Graduação Interdisciplinar em Estudos do Lazer (UFMG). Membra do grupo LUCE.

${ }_{2}^{2}$ Mestranda no Programa de Pós-Graduação Interdisciplinar em Estudos do Lazer (UFMG). Membra dos grupos FuLiA, Oricolé e Hisla.
} 


\section{Introdução}

O programa de Pós-Graduação Interdisciplinar em Estudos do Lazer da Universidade Federal de Minas Gerais (PPGIEL/UFMG) é o único programa específico sobre lazer no Brasil e único da América do Sul que oferta vagas a doutorandos. Nele coexistem os mais diversos grupos, pesquisadores e pesquisadoras, e uma extensa multiplicidade de pesquisas, fazendo jus a interdisciplinaridade que propõe. $O$ resultado disso pode ser vislumbrado tanto no banco de dados de teses e dissertações, quanto em revistas dos mais variados temas, e de forma mais específica, em duas revistas próximas ao programa, que possuem artigos de pesquisadores e pesquisadoras do lazer da própria UFMG, assim como de outros estudiosos do lazer dos mais diferentes lugares. Essas revistas são encontradas no portal de periódicos da Universidade Federal de Minas Gerais e se chamam: Licere (Revista do Programa de Pós-Graduação Interdisciplinar em Estudos do Lazer) e a RBEL (Revista Brasileira de Estudos do Lazer).

Alguns dos estudos publicados nesses periódicos, como iremos demonstrar mais adiante, têm como objetivo ou objeto o estudo do lazer das mulheres, ou, o lazer em relação às questões de gênero, com o olhar voltado à construção feminino/feminilidade.

O lazer, conceituado de inúmeras formas, inclusive como espaço de organização popular, de produção e socialização de conhecimento, faz com que nele estejam presentes papéis e comportamentos sociais. E sendo ele polissêmico, assim como ressalta Nascimento; Saldanha e Fidalgo (2019), expressa as contradições da sociedade:

\footnotetext{
Pode ser entendido de diversas formas: como tempo de recuperação das atividades laborais, como manifestação cultural, como necessidade humana, como privilégio ou direito social, como atividade educativa e enriquecedora ou prática alienante, como consumo, indústria ou mercado profissional (2019, p.670).
}

Dentro do campo do lazer, assim como em outras áreas, os estudos das mulheres ainda não são amplamente estudados e discutidos como deveriam. E o feminismo é uma 
urgência no mundo, principalmente nas periferias globais, como a América do Sul (ARRUZA; BHATTACHARYA E FRASER, 2019). Diante disso e diante dessa interdisciplinaridade do lazer, que se reflete em multiplicidade e diversidade de assuntos, torna-se fundamental pesquisar gênero, mulheres e feminismo. O objetivo deste estudo é analisar as produções sobre as mulheres dentro dos estudos do lazer por intermédio das duas revistas já citadas, visando compreender o que foi produzido, quais foram as principais contribuições, e, por fim, discutindo a possibilidade de novas reflexões e novas pesquisas sobre a temática.

O lazer, direito social presente no Artigo $6^{\circ}$ da Constituição (1988), precisa chegar a todos os grupos, principalmente nas minorias que ainda tem dificuldades de acesso a essas vivências, seja por dificuldades financeiras, para se locomover na cidade, por ausência de ofertas em bairros periféricos, por falta de dinheiro, por falta de tempo devido as duplas e triplas jornadas de trabalho, entre outras questões. Assim, o que justifica esse estudo é a necessidade de equidade das mulheres nesse campo social.

De acordo com Flax (1991), os estudos de gênero entram em qualquer aspecto da experiência humana. Dentro dos estudos do lazer é necessário que essas pesquisas tenham força e percepção crítica, visto que existem lacunas a serem preenchidas nos estudos de gênero dentro do campo. Para Sousa (1994), as pesquisas sobre gênero e lazer têm caráter emancipatório, se apresentando como um espaço possível para entender e romper com os valores sexistas. As atividades lúdicas têm grandes potencialidades nesse sentido.

Esse trabalho é classificado como uma revisão bibliográfica sistematizada que, segundo Maclure; Paudyal Sewart (2016) consiste em identificar, avaliar e interpretar pesquisas existentes em determinadas bases de dados. Logo após esse levantamento, 
partindo do pressuposto que existem lacunas a serem preenchidas em qualquer assunto, discutir sobre novas possibilidades de pesquisas.

\section{Metodologia}

Para realização da revisão de literatura, fizemos uma pesquisa no banco de dados das revistas Licere e RBEL, sendo o recorte temporal delimitado pelo período de criação de cada um desses periódicos (1998) e (2014), respectivamente, até o fim de 2020. A partir disso, foi feita uma busca de artigos na plataforma com as palavraschave: "mulheres", "mulher" e "gênero". A escolha das palavras buscou abarcar a totalidade de estudos sobre o assunto, evitando restrições fruto da opção por um único termo. Pesquisamos esses termos isoladamente em cada uma das revistas e consideramos apenas uma ocorrência nos casos de duplicidade.

Após essa busca nas revistas, excluímos os trabalhos que não se enquadravam nas seções "artigos originais", "artigos de revisão", "ensaios" e "relatos de experiência". Posteriormente, fizemos a leitura dos títulos, resumos e palavras-chave, e os trabalhos selecionados para análise final foram aqueles que possuíam relação com o tema de interesse, ou seja, com os estudos do lazer das mulheres.

A análise foi quanti-qualitativa, de naturezas diferentes, mas complementares. Segundo Minayo e Sanches (1993), a primeira tem como campo de práticas trazer luz a dados, indicadores e tendências, a segunda é voltada para aprofundar a complexidade desses fenômenos, fatos e processos observados. Dessa forma, os dados quantitativos nos darão questões para serem aprofundadas qualitativamente. Na leitura completa dos artigos selecionados, foi observado: 1) as quantidades de artigos por ano, na tentativa de compreender se esses estudos vêm aumentando, 2) a quantidade de artigos por gênero 
dos autores e autoras, 3) assunto tratado e 4) comparação com a quantidade total de artigos por ano em cada periódico.

Já na análise qualitativa, foram analisados os principais assuntos, suas similaridades e contrastes e as discussões que foram feitas pelos autores e autoras. Além disso, também foi observada a abordagem desses estudos em relação às questões de gênero, se essas pesquisas se aprofundaram na interseccionalidade que atravessa os estudos das mulheres e, por fim, qual a provável contribuição desses artigos para o campo de estudos em questão. Realizando, assim, a pesquisa da forma como Santos (2006) menciona para as revisões bibliográficas, que é trazer à tona o conhecimento produzido nesses periódicos e propor possibilidades para as pesquisas futuras.

\section{Os Estudos do Lazer}

Os estudos do lazer possuem várias abordagens teóricas e conceituais distintas. Há autores, como Frederic Munné (2002) que acreditam que o lazer já existia desde a antiguidade. Munné (2002) defende que a prática de lazer antecede à idade moderna, argumentando que o "ócio" se estrutura nas seguintes áreas de atividades (MUNNÉ, 2002, p. 59):

1) O tempo psicobiológico, ocupado basicamente pelas necessidades fisiológicas e psíquicas. 2) O tempo socioeconômico, fundamentalmente ligado ao trabalho. 3) O tempo sociocultural, especialmente dedicado à vida em sociedade. E 4 o tempo de ócio, destinado a atividades de desfrute social e coletivo.

A conceituação que consiste na ideia de que o lazer sempre existiu como argumenta Munné (2002), é refutada por outra perspectiva teórica, mais comum, que segue a lógica de que o lazer surgiu durante a Idade Moderna, após a Revolução Industrial. Os autores Melo e Drumond (2003) defendem essa perspectiva, afirmando que desde o final do século XVIII e a implementação do modelo de produção fabril, o 
tempo passou a ser dividido de forma distinta dentro da sociedade. A partir de então, o tempo dos trabalhadores foi dividido entre tempo de trabalho e o de não-trabalho. Para Melo e Drummond (2003), foi nesse processo típico da modernidade que se iniciou o que hoje caracterizamos como lazer. O lazer foi formado por uma tensão entre classes e da dinâmica resultante disso, e é, portanto, marcado pelas contradições entre controle/resistência, adequação/subversão, consciência/alienação.

Melo e Drummond (2003) discutem, portanto, que a partir dessa construção social e desses mecanismos de embates entre a classe dominante e os trabalhadores, além da nova forma como se configurou o tempo no dia a dia dentro das sociedades, o lazer passou a fazer parte dessa conjectura, se tornando uma forma às vezes alienante, às vezes conscientizante, das pessoas se aliviarem do dia a dia das fábricas.

O sociólogo francês Dumazedier foi o primeiro cujo conceito e caracterização do lazer foi mais amplamente difundido no Brasil. Segundo o autor, o lazer seria um conjunto de ocupações às quais o indivíduo dispõe-se de livre vontade para repousar, divertir-se, recrear-se ou entreter-se, podendo, ainda, desenvolver sua informação ou formação desinteressada, sua participação social voluntária ou sua livre capacidade criadora após livrar-se ou desembaraçar-se das obrigações profissionais, familiares e sociais (DUMAZEDIER, 1973). Com a conceituação de Dumazedier, foi possível compreender o tempo como um aspecto fundamental na conceituação de lazer, pois o indivíduo precisa estar desfrutando totalmente de seu período destituído de obrigações para, de fato, estar em uma vivência de lazer.

Outra linha teórica afirma que o lazer é, na realidade, uma necessidade humana e dimensão da cultura (GOMES, 2014). O autor brasileiro Marcellino (1987) foi um dos pioneiros ao abordar o lazer, conceituando-o como forma de cultura, e compreendida no seu sentido mais amplo, sendo vivenciada (praticada ou fruída) no tempo disponível. 
Segundo Marcellino (1987), o lazer, ainda ligado ao aspecto tempo, deve considerar as atividades desenvolvidas no tempo liberado do trabalho - no tempo livre ou disponível, destituído das obrigações profissionais, familiares, sociais e religiosas (MARCELLINO, 2000).

Essas linhas diferentes de conceituação do lazer são utilizadas de diferentes formas pelos artigos aqui abordados, porém não há um consenso em sua definição. Assim sendo, não nos ateremos a essa discussão e não utilizamos também uma definição única dentro desse estudo.

\section{Os Estudos de Gênero e das Mulheres}

Os estudos das mulheres estão presentes dentro dos estudos de gênero, palavra que, sintaticamente, segundo o dicionário Michaelis "Conceito de ordem geral que abrange todas as características ou propriedades comuns que especificam determinado grupo ou classe de seres ou de objetos." Diante dessa ideia de gênero, é necessário compreender o sistema gênero-sexo que é conceituado por Laurentis (1987, p. 211) como:

\footnotetext{
Uma construção sociocultural quanto um aparato semiótico, um sistema de representação que atribui significado (identidade, valor, prestígio, posição e parentesco, status dentro da hierarquia social etc.) a indivíduos dentro da sociedade.
}

Sendo assim, quando é utilizada a terminologia "gênero feminino", estamos nos referindo a um sistema de representações socioculturais especificamente criadas para a mulher.

O conceito de gênero é diverso e, assim, presente em variadas teorias sociais, sendo relevante para esse estudo citar as mais difundidas no meio acadêmico. Butler (1990) é uma das autoras cuja conceituação de gênero é mais conhecida, sendo utilizada inclusive em discussões e pesquisas dentro das revistas que foram analisadas. Para ela: 
O gênero pode também ser designado como o verdadeiro aparato de produção através do qual os sexos são estabelecidos. Assim, o gênero não está para a cultura como o sexo para a natureza; o gênero é também o significado discursivo/cultural pelo qual a 'natureza sexuada' ou o 'sexo natural' é produzido e estabelecido como uma forma 'pré-discursiva' anterior à cultura, uma superfície politicamente neutra sobre a qual a cultura age (1990, p. 7).

Scott (1989), autora que também elaborou várias pesquisas dentro dos estudos de gênero, compreende todo o sistema de relações que constitui a relação social construída historicamente entre homens e mulheres. Scott (1989) afirma que:

Minha definição de gênero tem duas partes e várias subpartes. Elas são ligadas entre si, mas deveriam ser analiticamente distintas. O núcleo essencial da definição baseia-se na conexão integral entre duas proposições: o gênero é um elemento constitutivo de relações sociais baseado nas diferenças percebidas entre os sexos, e o gênero é uma forma primeira de significar as relações de poder (SCOTT, 1989, p.28).

Já durante a segunda onda ${ }^{3}$ do feminismo em 1949, Beauvoir lançou o livro "O segundo sexo". Nessa obra, apesar de não utilizar o termo, apresenta a ideia de gênero ao contestar o determinismo biológico, afirmando a célebre ideia de que não se nasce mulher, mas torna-se.

O sujeito é constituído em seu gênero por meio de códigos linguísticos e representações culturais (LAURENTIS, 1987). Ou seja, ao passo que o sexo biológico é, supostamente, aquilo que determina biologicamente o homem e a mulher, a diferenciação sexual que ocorre entre esses dois sujeitos advém mais da construção representativa de uma visão que a sociedade construiu sob os corpos desses sujeitos. Portanto, é necessário compreender o gênero.

Com o despertar das mulheres e as consequentes Ondas Feministas, as questões de gênero se tornaram fonte de debate e discussões, tanto nas ruas quanto no meio

\footnotetext{
${ }^{3}$ Segundo Caetano (2017), a primeira onda do feminismo no Brasil foi em meados do século XIX com reivindicações ligadas ao reconhecimento dos direitos políticos, sociais e econômicos das mulheres. A segunda onda inicia por volta de 1960, ganhando força na ditadura militar, tendo como característica a luta pela proteção da mulher e suas especificidades. Já a terceira onda busca desenvolver o próprio conceito da categoria "mulher" enquanto categoria pretensamente universal, e considera importante questões como etnia, sexualidade, classe e afins. Essa terceira fase tem caráter interseccional e é onde nos encontramos na atualidade.
} 
acadêmico. As novas formas de ser e pensar-se mulher aumentou tanto com o aumento de estudos sobre o assunto, quanto com a ampliação das discussões dentro e fora do ambiente acadêmico. Alguns direitos foram conquistados por meio das inúmeras lutas feministas fruto destes questionamentos, porém, ainda se faz necessário ampliar as pesquisas e discussões, visando finalmente superar o machismo e o patriarcado que ainda se fazem presentes (ALVES; PITANGUY, 1982).

As mulheres sofreram séculos de silenciamento e submissão e, apesar de várias já terem se rebelado contra o sistema patriarcal ao longo desse tempo, com a consolidação do sistema capitalista a situação ficou ainda mais insustentável. Durante o século XIX, e com os processos produtivos de organização do trabalho, assim como a utilização da mão de obra feminina, as reivindicações das mulheres precisaram se fortalecer, pois possuíam um agravante, além de dividir as condições precárias do trabalho na época, elas ainda trabalhavam em suas casas, realizando uma das tarefas mais importantes de garantia da reprodução social, e ainda sofrendo com a superexploração das diferenças salariais (ALVES; PITANGUY, 1982).

Com a inserção da mulher dentro desse modelo fabril, elas passaram a reivindicar um espaço de voz entre os sindicatos. Porém, os sindicatos lhes fecharam as portas, tratando-as como "correntes desleais" do movimento. Algumas líderes revolucionárias surgiram nessa época se organizando para lutar, juntamente com os homens, a favor de interesses comuns para toda a classe operária. Assim, por meio dessas lutas constantes, as mulheres conseguiram romper um pouco do silêncio secular ao qual estavam limitadas e projetaram reivindicações na esfera pública (ALVES; PITANGUY, 1982). Dessa forma, surgiu o feminismo, que inicialmente apenas buscava igualdade salarial e condições de trabalho semelhantes, assim como o direito ao voto, porém, esse movimento cresceu, evoluindo ao que existe até hoje. 
Segundo Oliveira (1969), o feminismo é um movimento social cuja finalidade é a equiparação dos sexos relativamente ao exercício dos direitos cívicos e políticos (OLIVEIRA, 1969, p.424). Ou seja, o feminismo é uma busca pelos direitos iguais entre os gêneros e pelo fim das práticas sexistas que oprimem e excluem as mulheres de seus direitos. O feminismo, assim como afirmam Arruza; Bhattacharya e Fraser (2019) precisam que a maioria das mulheres caiba nele, pois nem todo feminismo liberta, emancipa e acolhe, ele precisa ser um feminismo que leve em consideração as mulheres mais exploradas (negras, periféricas, pobres), portanto, o feminismo precisa também ser anticapitalista.

Dessa forma, os estudos de gênero surgiram a partir dos desdobramentos do próprio movimento feminista, assim como o contexto cultural e social do pós Segunda Guerra Mundial. Meira (2014) analisa que o período pós guerra foi um momento de efervescência mundial, gerando novas contestações: "Num mundo pós Segunda Guerra Mundial, no auge da estabilidade econômica, mas fragilizado pelos conflitos da Guerra Fria, todo o conjunto de grandes narrativas, com marcos e paradigmas históricos estabelecidos, foi posto à prova" (MEIRA, 2014, p. 204). Foi a partir dessa estrutura mundial e com o surgimento do individualismo e da urbanização da sociedade, que a Revolução Cultural ocorreu, segundo Meira (2014), levantando debates importantes para os sujeitos sociais, individuais ou coletivos. Os indivíduos passaram a se questionar e o mundo ao redor, levando ao surgimento de movimentos como o movimento negro, feminismo, hippies, pacifistas, entre outros. Dessa forma, a partir da revolução a experiência se desdobrou em variadas possibilidades de representações históricas, como as Escolas Metódicas e Positivistas, o Marxismo e os Estudos de Gênero (HOBSBAWM, 1994; MEIRA, 2014). 
Esses estudos, juntamente com os movimentos feministas, se encontram num momento histórico em que a mulher está, cada vez mais, discutindo o seu papel e função na sociedade. Apesar do longo caminho que ainda precisa ser percorrido pelo movimento feminista e pelos estudos de gênero, na atualidade, existem muitos movimentos em que as mulheres buscam quebrar estereótipos, seja nos debates sociais ou acadêmicos. O feminismo interseccional é um ótimo exemplo de luta que ainda precisa se difundir e ganhar espaço, mas que adota uma posição de combate às desigualdades que se interseccionam a partir de certos marcadores sociais, como gênero, raça e classe social. Uma das grandes autoras precursoras dessa ideia é Angela Davis (2016), que afirma que as questões de desigualdade de gênero são ampliadas ou diminuídas quando estão em conjunto com esses outros marcadores sociais. Outra autora que fala sobre isso é Kimberlé Crenshaw. Para Crenshaw (1994), a interseccionalidade está focada principalmente nas questões de raça, gênero e classe, levantando questões como as múltiplas fontes de identidade que as mulheres podem possuir, dependendo de onde vivem, e o tipo de machismo a que estão submetidas. Assim, Crenshaw e Davis possuem foco na diversidade que o gênero feminino pode ter nas suas lutas.

Já nos aproximando da realidade brasileira, Silva (2000), diz que os estudos de gênero no Brasil acompanharam os movimentos feministas que foram acontecendo pelo mundo, e que após a década de 1980, depois de uma ditadura militar, o campo foi começando a ser melhor consolidado. Alinhado a essa linha temporal e pensando na realidade dos Estudos do Lazer, houve um crescimento nos estudos do lazer desde a década de 1960 e o com mais força a partir da década de 1970 (MELO, 2003). Porém a união dessas discussões demorou a acontecer como é mostrado adiante. 
Para alterar essa realidade dentro do ambiente acadêmico, possibilitando o aumento de debates sobre esses temas nos movimentos sociais, é fundamental analisar qual é a situação das discussões sobre gênero e sobre mulher, quais os aspectos, temas e pesquisas a respeito. A partir disso, é possível visualizar melhor as lacunas e investir em temas significativos para a sociedade e, também, para o campo dos Estudos do Lazer. Portanto, a seguir, elaboramos um levantamento sobre as pesquisas nos periódicos Licere e RBEL ao longo dos anos.

\section{Resultados e Discussões}

A revista Licere é vinculada ao sistema de periódicos da UFMG e também ao programa de pós-graduação Interdisciplinar em Estudos do Lazer. Ela é publicada trimestralmente e tem como objetivo aumentar as discussões sobre o lazer nas mais diferentes áreas. Já a revista RBEL, também vinculada a UFMG, tem associação com a ANPEL e é publicada quadrimestralmente, e seu objetivo é similar ao da revista Licere, de aumento e difusão das discussões sobre lazer. A Licere tem publicações desde o ano de 1998 e a RBEL desde 2014.

Como dissemos na metodologia, foi pesquisado em cada um desses periódicos, isoladamente, as palavras "Mulheres", "Mulher" e "Gênero". Logo após essa busca, retiramos as duplicidades, e aqueles que não se enquadravam nas seções "artigo original", "artigo de revisão", e "Relatos de experiência". Posteriormente fizemos a leitura dos títulos, palavras-chave e resumos que apareceram nesta pesquisa para selecionar quais artigos estavam voltados aos estudos das mulheres. Desta análise, foram excluídos os artigos sobre gênero que tratassem, por exemplo, de masculinidades, e os estudos mais gerais que faziam breves comparações entre os gêneros, mas não tinha como objetivo pesquisar as mulheres em si. Restaram os artigos que faziam discussões 
sobre gênero, mulheres, feminismo, e sobre os que pesquisavam exclusivamente em uma população feminina.

\section{Quadro 1: Artigos selecionados na revista Licere.}

\begin{tabular}{|c|c|c|c|}
\hline Título do texto & Revista & Autor (es) & Ano \\
\hline $\begin{array}{l}\text { Valeu o Boi! Uma Análise de Gênero Sobre } \\
\text { a Prática de Mulheres na Vaquejada }\end{array}$ & LICERE & $\begin{array}{l}\text { Anyelle Brito Leite Santos, } \\
\text { Tassia de Souza Cavalcanti, } \\
\text { Camila Batista Gama Moura, } \\
\text { Diego Luz Moura }\end{array}$ & 2020 \\
\hline $\begin{array}{l}\text { Perspectivas sobre o Lazer das Mulheres } \\
\text { com a Pandemia do Novo Coronavírus } \\
\text { Reflexões a partir dos Dados da Pesquisa } \\
\text { "O Lazer no Brasil - Representações e } \\
\text { Concretizações das Vivências Cotidianas" }\end{array}$ & LICERE & $\begin{array}{l}\text { Sarah Teixeira Soutto Mayor, } \\
\text { Marcília de Sousa Silva, } \\
\text { Carolina Gontijo Lopes }\end{array}$ & 2020 \\
\hline $\begin{array}{l}\text { O Lazer nas Conferências e nos Planos } \\
\text { Nacionais de Políticas para as Mulheres }\end{array}$ & LICERE & $\begin{array}{l}\text { Cláudia Regina Bonalume, } \\
\text { Hélder Ferreira Isayama }\end{array}$ & 2020 \\
\hline $\begin{array}{l}\text { Da Participação de Mulheres no Futebol em } \\
\text { Barbacena/MG nas Três Primeiras Décadas } \\
\text { do Século XX }\end{array}$ & LICERE & $\begin{array}{l}\text { Igor Maciel Silva, Maria } \\
\text { Cristina Rosa }\end{array}$ & 2020 \\
\hline $\begin{array}{l}\text { Sociabilidade e Lazer entre Mulheres } \\
\text { Camponesas Vivências no Clube de Mães }\end{array}$ & LICERE & $\begin{array}{l}\text { Josiane Carine Wedig, } \\
\text { Angélica Servegnini de } \\
\text { Wallau, Ana Flávia Padilha, } \\
\text { André Luiz Simonetti }\end{array}$ & 2020 \\
\hline $\begin{array}{l}\text { Avaliação dos Estados de Humor e } \\
\text { Qualidade de Vida de Idosas em Diferentes } \\
\text { Contextos de Vida e a Percepção da } \\
\text { Importância do Lazer }\end{array}$ & LICERE & $\begin{array}{l}\text { Bárbara Beatriz Ferreira Silva, } \\
\text { Amanda Alves da Silva, } \\
\text { Gislane Ferreira de Melo, } \\
\text { Isabelle Patriciá Freitas } \\
\text { Soares Chariglione }\end{array}$ & 2019 \\
\hline $\begin{array}{l}\text { Currículos e Resistências "Libertem Ângela } \\
\text { Davis e Todos os Presos Políticos" }\end{array}$ & LICERE & $\begin{array}{l}\text { Lucas Vinícius Cintra } \\
\text { Mendes, Cathia Alves }\end{array}$ & 2019 \\
\hline $\begin{array}{l}\text { Lazer e Cinema Simbolismos e } \\
\text { Representações de Gênero no Filme "Boi } \\
\text { Neon" }\end{array}$ & LICERE & Christianne Luce Gomes & 2019 \\
\hline $\begin{array}{l}\text { Empoderamento, Mulheres e Práticas } \\
\text { Corporais }\end{array}$ & LICERE & $\begin{array}{l}\text { Tássia de Souza Cavalcanti, } \\
\text { Roberta de Sousa Mélo, } \\
\text { Anyelle Brito Leite Santos, } \\
\text { Camila Batista Gama Moura, } \\
\text { Diego Luz Moura }\end{array}$ & 2018 \\
\hline $\begin{array}{l}\text { Manifestação de Lazer na História de Vida } \\
\text { de Idosas do Grupo Pioneiras de Rondônia } \\
\text { Práticas de Lazer na Fase Adulta }\end{array}$ & LICERE & $\begin{array}{l}\text { Ivete de Aquino Freire, } \\
\text { Ramón Núñes Cárdenas, Rosa } \\
\text { de Luz Ambrósio dos Reis } \\
\text { Miranda Sá, Ednes Pereira } \\
\text { dos Santos Souza, Paola Lima } \\
\text { Tristão }\end{array}$ & 2018 \\
\hline
\end{tabular}


Os Estudos sobre as Mulheres no Lazer nos Periódicos Licere e RBEL Julia Drumond Cunha e Verônica Toledo Ferreira de Carvalho

\begin{tabular}{|c|c|c|c|}
\hline $\begin{array}{l}\text { Experiências Pedagógicas a Partir de } \\
\text { Histórias em Quadrinhos de Super-Heróis } \\
\text { Educação para o Lazer }\end{array}$ & LICERE & $\begin{array}{l}\text { Cinthia Lopes da Silva, } \\
\text { Marília Cezarino, Lucas de } \\
\text { Andrade Carvalho, Marcio } \\
\text { Ferreira de Souza }\end{array}$ & 2018 \\
\hline $\begin{array}{l}\text { Surfe é Estilo de Vida: Motivação Para a } \\
\text { Prática em Mulheres Jovens }\end{array}$ & LICERE & $\begin{array}{l}\text { Gerson Paulo Pereira Neto, } \\
\text { Ewerton Sousa de Abreu, } \\
\text { Jessica de Freitas Nascimento, } \\
\text { Bráulio Nogueira de Oliveira, } \\
\text { André Accioly Nogueira } \\
\text { Machado }\end{array}$ & 2017 \\
\hline Futebol, Mulheres e Interação Social & LICERE & $\begin{array}{l}\text { Alexandre Jackson Chan- } \\
\text { Vianna, Diego Luz Moura }\end{array}$ & 2017 \\
\hline $\begin{array}{l}\text { Dança para Educar e Entreter, o Curso } \\
\text { Natália Lessa em Belo Horizonte (1928- } \\
\text { 1960) }\end{array}$ & LICERE & Elisangela Chaves & 2016 \\
\hline $\begin{array}{l}\text { Lazer e cinema: Representações das } \\
\text { Mulheres em Filmes Latino-Americanos } \\
\text { Contemporâneos }\end{array}$ & LICERE & Christianne Luce Gomes & 2016 \\
\hline $\begin{array}{l}\text { Surfe Feminino, Indústria do Surfwear e } \\
\text { Promoção da África do Sul } \\
\text { Uma Análise de A Onda dos Sonhos } 2\end{array}$ & LICERE & Rafael Fortes & 2014 \\
\hline $\begin{array}{l}\text { Das Senhoras e Senhorinhas nos "Grounds" } \\
\text { do Sport Bretão: A História da Mulher nos } \\
\text { Campos de Futebol em Belo Horizonte/MG } \\
(1904 \text {-1920) }\end{array}$ & LICERE & $\begin{array}{l}\text { Georgino Jorge de Souza } \\
\text { Neto, Priscila Augusta } \\
\text { Ferreira Campos, Silvio } \\
\text { Ricardo da Silva }\end{array}$ & 2013 \\
\hline $\begin{array}{l}\text { As Relações de Gênero na Opção de Lazer } \\
\text { de Pessoas Atuantes em Cooperativas de } \\
\text { Trabalho }\end{array}$ & LICERE & $\begin{array}{l}\text { Daniel Bidia Olmedo Tejera, } \\
\text { Ioranny Raquel Castro de } \\
\text { Sousa, Tânia Mara Vieira } \\
\text { Sampaio }\end{array}$ & 2013 \\
\hline $\begin{array}{l}\text { Restrições ao Lazer Feminino } \\
\text { Particularidades das Experiências de Lazer } \\
\text { de Mulheres Homossexuais }\end{array}$ & LICERE & $\begin{array}{l}\text { Carla Barbosa, Toni Liechty, } \\
\text { Raquel Pedercini }\end{array}$ & 2013 \\
\hline $\begin{array}{l}\text { Preferências de Atividades de Lazer de um } \\
\text { Grupo de Idosas do Extremo Sul do Brasil' }\end{array}$ & LICERE & $\begin{array}{l}\text { Luiza Isnardi Cardoso } \\
\text { Ricardo, José Antônio Bicca } \\
\text { Ribeiro, Rodrigo Wiltgen } \\
\text { Ferreira, Adriana Schüler } \\
\text { Cavalli }\end{array}$ & 2013 \\
\hline $\begin{array}{l}\text { Lazer e Gênero nos Programas de Esporte e } \\
\text { Lazer das Cidades }\end{array}$ & LICERE & $\begin{array}{l}\text { Silvana Vilodre Goellner, } \\
\text { Sebastião Josué Votre, } \\
\text { Ludmila Mourão, Márcia } \\
\text { Luiza Machado Figueira }\end{array}$ & 2010 \\
\hline $\begin{array}{l}\text { As Mulheres no Cenário do Associativismo } \\
\text { Esportivo em Porto Alegre/RS na Transição } \\
\text { do Século XIX para o XX }\end{array}$ & LICERE & $\begin{array}{l}\text { Janice Zarpellon Mazo, } \\
\text { Carolina Fernandes da Silva, } \\
\text { Vanessa Bellani Lyra }\end{array}$ & 2010 \\
\hline
\end{tabular}

Fonte: Elaborado pelas autoras a partir dos dados da busca nos periódicos Licere. 
A primeira busca no periódico, feita com o termo "mulheres", resultou em 66 artigos, a segunda, com o termo "mulher", resultou em 19 artigos, e a terceira, "gênero", teve 48 ocorrências. Aplicados os critérios de exclusão e inclusão, foram selecionados 22 artigos da revista Licere.

Desses 22 artigos, 2 foram publicados no ano de 2010, 3 no ano de 2013, 2 no ano de 2014, 2 em 2016, 2 em 2017, 3 em 2018, 3 em 2019 e 5 em 2020. Ou seja, entre 2010 e 2017 a média de artigos sobre o assunto girava entre 1 e 2, já a partir de 2018 foi quando o tema passou a ser mais pesquisado. Percebemos então um leve crescimento desses estudos. Vale ressaltar ainda que, dos 60 autores presentes nesses artigos, 38 são mulheres e 22 são homens.

Quadro 2: Artigos selecionados na revista RBEL.

\begin{tabular}{|c|c|c|c|}
\hline Título do texto & Revista & Autor (es) & Ano \\
\hline $\begin{array}{l}\text { Barreiras de acesso ao lazer das mulheres } \\
\text { segundo raça/cor e classe social nas regiões } \\
\text { sudeste e nordeste do Brasil. }\end{array}$ & RBEL & $\begin{array}{l}\text { Sarah Teixeira Soutto Mayor, } \\
\text { Marília Martins Bandeira, Igor } \\
\text { Maciel da Silva, Edmur } \\
\text { Antônio Stoppa, Hélder } \\
\text { Ferreira Isayama }\end{array}$ & 2020 \\
\hline $\begin{array}{l}\text { "Lazer?! Para mim?!" Consumo de lazer } \\
\text { por mulheres de baixa renda. }\end{array}$ & RBEL & $\begin{array}{l}\text { Georgiana Luna Batinga, } \mathrm{M} \text {. } \\
\text { R. Pinto }\end{array}$ & 2019 \\
\hline $\begin{array}{l}\text { Políticas Públicas de Financiamento de } \\
\text { pesquisas: a participação das mulheres no } \\
\text { âmbito dos Estudos do Lazer e do Esporte }\end{array}$ & RBEL & $\begin{array}{l}\text { Maria Clara Elias Polo, Giselle } \\
\text { Helena Tavares }\end{array}$ & 2019 \\
\hline $\begin{array}{l}\text { Corpo e feminilidade a partir da experiência } \\
\text { das jogadoras de Rugby brasileiras. }\end{array}$ & RBEL & $\begin{array}{l}\text { Marco Bettine Almeida, Diego } \\
\text { Monteiro Gutierrez, Alua } \\
\text { Oliveira }\end{array}$ & 2017 \\
\hline $\begin{array}{l}\text { As mulheres na pesquisa O Lazer do } \\
\text { Brasileiro. }\end{array}$ & RBEL & $\begin{array}{l}\text { Cláudia Regina Bonalume, } \\
\text { Hélder Ferreira Isayama }\end{array}$ & 2018 \\
\hline $\begin{array}{l}\text { O cinema como experiência de lazer e as } \\
\text { personagens femininas do filme "Para } \\
\text { minha amada morta": Assimilando valores, } \\
\text { desvelando significados. }\end{array}$ & RBEL & $\begin{array}{l}\text { Christianne Luce Gomes, } \\
\text { Maria de Fátima Queiroz } \\
\text { Costa Maia, Mariana Rosalina } \\
\text { Cordeiro Ferreira Silva, } \\
\text { Renata Gontijo }\end{array}$ & 2016 \\
\hline $\begin{array}{l}\text { Território funk e feminilidades: } \\
\text { Subjetividades construídas entre relações de } \\
\text { poder, a rua e a violência. }\end{array}$ & RBEL & Iara Pires Viana & 2016 \\
\hline
\end{tabular}


Atividades de lazer no contexto hospitalar: Uma estratégia de humanização.
RBEL

Iara Mendes Florentino, Maria José Gugelmin de Camargo
2015

Fonte: Elaborado pelas autoras a partir dos dados da busca nos periódicos Licere.

Já na Revista Brasileira de Estudos do Lazer, foram selecionados 8 artigos. O número, reduzido se comparado com a revista Licere, tem associação com o tempo de criação da revista RBEL, que é mais recente. A busca na plataforma, teve os seguintes resultados: o termo "mulheres" resultou em 16 artigos, o termo "mulher" foram identificados 5, enquanto "gênero" selecionou 7. Foram selecionados 8 artigos para análise.

Desses artigos, 1 foi publicado no ano de 2016, 2 artigos em 2017, 3 em 2018 e 3 em 2020. Destacamos que são, ao todo, 19 autores responsáveis por esses 8 artigos, sendo 13 deles mulheres e 6 homens. Houve também um aumento dos estudos a respeito de gênero e mulheres na revista RBEL, se comparado aos primeiros anos de revista.

Portanto, olhando para esses periódicos, percebe-se um crescente processo de aumento do número de artigos publicados e, também, de pessoas interessadas a respeito dos estudos sobre mulheres dentro do campo do lazer. Houve um aumento no número de publicações em ambas as revistas, porém o número ainda não é massivo se for considerado que, ao todo na busca, foram encontrados apenas 30 artigos.

A partir disso, agrupamos as pesquisas por assunto, dividindo-as em: 1) Artigos classificados como "lazer da mulher" - aqueles que tiveram pesquisas, entrevistas, etnografias e afins com algum grupo populacional feminino 2) Lazer e esporte - com pesquisas onde um ou mais esportes seja um dos principais assuntos, 3) Lazer no Brasil - artigos que foram resultados da pesquisa "Lazer do Brasil" 4) Lazer e cinema - com pesquisas sobre mulheres e o cinema, 5) Lazer e cultura - com pesquisas diversas no 
âmbito cultural. 6) Lazer e História - com artigos sobre mulheres e as diversões em períodos anteriores a contemporaneidade, 7) Lazer e políticas públicas - com artigos sobre as políticas públicas para as mulheres e por fim 8) Lazer e artigos de revisão com os artigos que fizeram revisão bibliográfica e não estiveram presentes nos grupos anteriores. Alguns se encaixaram em um ou mais grupos.

Os temas apresentaram amplas variedades, sendo que o lazer da mulher é destacadamente o mais recorrente. Artigos como "Sociabilidade e Lazer entre Mulheres Camponesas Vivências no Clube de Mães”, “Avaliação dos Estados de Humor e Qualidade de Vida de Idosas em Diferentes Contextos de Vida e a Percepção da Importância do Lazer”, "Manifestação de Lazer na História de Vida de Idosas do Grupo Pioneiras de Rondônia Práticas de Lazer na Fase Adulta" e "Preferências de Atividades de Lazer de um Grupo de Idosas do Extremo Sul do Brasil”, por exemplo, focam em descrever e compreender como se dá a vivência de lazer de grupos específicos de mulheres, em realidades singulares. Esse tipo de estudo apresenta grande relevância nos Estudos de Lazer, pois permite entender como o gênero, em suas diversas vivências, experiências e individualidades, consegue extrair práticas de lazer capazes de renovar sua rotina, estabelecendo uma melhoria da saúde, tanto mental como física. As mulheres possuem especificidades diferentes dos homens, de forma que esses estudos de casos aprofundam e elaboram melhor essas questões.

Assim, nas experiências de lazer das mulheres, percebe-se a importância do esporte, como destacado nos artigos "Corpo e feminilidade a partir da experiência das jogadoras de Rugby brasileiras", "Futebol, Mulheres e Interação Social" e "Surfe é Estilo de Vida: Motivação Para a Prática em Mulheres Jovens". Esses artigos relacionam as práticas de esportes às vivências de lazer para mulheres e grupos específicos, seguindo também a linha anteriormente mencionada. Vários esportes são 
contemplados nessas vivências, como o surfe, futebol, rugby e voleibol, que vão desde estudos etnográficos, como em "Futebol, Mulheres e Interação Social", fazendo uma análise de expressões de feminilidades, às pesquisas localizadas, como o "Surfe é Estilo de Vida: Motivação para a prática em mulheres jovens", que pesquisou 20 mulheres para abordar o assunto. É perceptível como os artigos focaram a relevância do esporte para o bem estar dessas mulheres, que se conecta também aos seus estilos de vida, de construções e percepções individuais, além de discutirem sobre a relação com qualidade de vida.

As pesquisas do livro "Lazer no Brasil", elaborado por Edmur Antonio Stoppa e Hélder Ferreira Isayama, também resultaram em alguns artigos dos pesquisadores e pesquisadoras presentes no livro, juntamente com outros colaboradores. Alguns desses trabalhos que estavam associados aos estudos das mulheres, foram: "Perspectivas sobre o Lazer das Mulheres com a Pandemia do Novo Coronavírus Reflexões a partir dos Dados da Pesquisa “O Lazer no Brasil - Representações e Concretizações das Vivências Cotidianas" e "As mulheres na pesquisa O Lazer do Brasileiro" e o mais recente "Barreiras de acesso ao lazer das mulheres segundo raça/cor e classe social nas regiões sudeste e nordeste do Brasil". Essas pesquisas se destacam por sua abrangência e por levarem em consideração a interseccionalidade que atravessa os estudos das mulheres, como a região onde elas vivem, a classe social, etc. O mais recente deles, "Barreiras de acesso ao lazer das mulheres segundo raça/cor e classe social nas regiões sudeste e nordeste do Brasil", comenta sobre as barreiras a esse acesso e como as mulheres são as mais prejudicadas, principalmente no nordeste, sendo as barreiras mais relatadas: tempo e dinheiro. Outro que merece ser comentado, é que, a partir desse amplo estudo, que encorpa outros dados, foi possível realizar a pesquisa sobre o lazer das mulheres durante 
a pandemia já que os dados anteriores favoreceram a discussão sobre o que se esperava dessa situação.

Outra prática de lazer em destaque foi o cinema, cujos estudos a respeito resultaram em artigos, tais como, "Lazer e Cinema Simbolismos e Representações de Gênero no Filme "Boi Neon", "Representações das Mulheres em Filmes LatinoAmericanos Contemporâneos" e "O cinema como experiência de lazer e as personagens femininas do filme "Para minha amada morta": Assimilando valores, desvelando significados". Esses artigos focam em analisar o cinema como forma de representação da mulher, compreendendo o universo fílmico como um ambiente que produz e reproduz significações que estão de acordo com a nossa cultura, além de também ser um campo de comunicação e elaboração de discursos próprios. O artigo "Surfe Feminino, Indústria do Surfwear e Promoção da África do Sul: Uma Análise de A Onda dos Sonhos 2" também faz uma análise a respeito do cinema e discurso, porém ao invés de analisá-lo como representação das mulheres aborda o filme focando no conteúdo e compreendo a cultura do surfe dentro da narrativa.

Seguindo na análise da representação da mulher dentro de produções midiáticas, o artigo "Experiências Pedagógicas a Partir de Histórias em Quadrinhos de SuperHeróis Educação para o Lazer” também aborda a representação de mulheres, porém, voltado ao universo das HQs, com a realização de um estudo de caso. Tanto esse artigo, quanto os artigos sobre cinema entram na linha de lazer como forma de cultura e, sobre esse tema, os artigos "Valeu o Boi! Uma Análise de Gênero Sobre a Prática de Mulheres na Vaquejada" e "Currículos e Resistências "Libertem Ângela Davis e Todos os Presos Políticos”, abordam as mulheres e as opressões de gênero dentro de contextos culturais específicos e experiências de lazer. 
$\mathrm{Na}$ linha historiográfica, encontramos 3 artigos "Dança para Educar e Entreter, o Curso Natália Lessa em Belo Horizonte (1928-1960)", "Das Senhoras e Senhorinhas nos "Grounds" do Sport Bretão: A História da Mulher nos Campos de Futebol em Belo Horizonte/MG (1904 -1920)” e “As Mulheres no Cenário do Associativismo Esportivo em Porto Alegre/RS na Transição do Século XIX para o XX”. Os estudos históricos, que são importantes para compreensão do passado para superação de situações do presente, parecem ter um número muito reduzido de pesquisas sobre as mulheres e as diversões, principalmente se pensarmos que os estudos do lazer ainda têm deficiências de estudos históricos, inclusive para compreensão da própria construção do termo, e, ter noções históricas de divertimentos para minorias, pode ajudar na construção desta ideia.

Esse mesmo problema se repete na temática políticas públicas para mulheres, onde só encontramos 3 artigos relacionados, sendo eles: "O Lazer nas Conferências e nos Planos Nacionais de Políticas para as Mulheres", Políticas Públicas de Financiamento de pesquisas: a participação das mulheres no âmbito dos Estudos do Lazer e do Esporte" e "Lazer e Gênero nos Programas de Esporte e Lazer das Cidades." No primeiro, os autores demonstram a timidez da demanda nos direitos reivindicados, o segundo comenta da necessidade de maior articulação do tema e o terceiro mostra os impedimentos das mulheres nas mesmas práticas de lazer dos homens. A própria constatação desses artigos, da deficiência do tema nas políticas públicas, ou das barreiras dessas mulheres, demonstra o quão necessário é discutir formas de viabilizar essas vivências para esse grupo.

Há também 2 revisões bibliográficas abordando temas diferentes sobre o lazer das mulheres, uma sobre o lazer para mulheres pertencentes à população LGBTQ+, chamado "Restrições ao Lazer Feminino Particularidades das Experiências de Lazer de Mulheres Homossexuais". Nele as autoras fazem revisão sobre a experiência de lazer de 
mulheres lésbicas, apresentando um panorama e pretendendo contribuir com estudos futuros. Existindo apenas um estudo que trata da temática LGBTQ+, nos faz questionar ainda mais a hierarquia de alguns temas dentro dos estudos de gênero, em que algumas mulheres são mais marginalizadas, e suas discussões menos viabilizadas.

$\mathrm{Na}$ mesma linha do nosso artigo, foi encontrado "Empoderamento, Mulheres e Práticas Corporais", um estudo que também faz uma busca nas bases de dados Scielo, Web of Science, Lilacs, Pubmed, Medline e Scopus, entre os anos de 2005 e 2015, sobre o empoderamento de mulheres em práticas corporais e assim como nossa pesquisa, também aponta carência de estudos sobre o assunto.

Percebendo que os primeiros artigos são encontrados em 2010, podemos nos questionar sobre a consolidação dos estudos de gênero e de lazer que, individualmente, começaram a se fortalecer após a década de 1960, porém, de acordo com nossos resultados, a união deles é recente. O lazer, enquanto espaço que reproduz comportamentos sociais, mas também pode organizar, educar e politizar os sujeitos, deve chegar a todos e a todas, e o movimento feminista, que necessita de espaço para educar, dialogar e organizar as mulheres, pode encontrar no lazer um grande aliado.

Algo importante a ser considerado nesta análise, é a quantidade de artigos total dos periódicos e quantos desses são relacionados ao lazer das mulheres. Dos 984 artigos presentes nas 2 revistas, apenas 30 se enquadram nos critérios selecionados dessa pesquisa. Houve também um aumento observado durante os anos na revista Licere, que pode explicar o aumento também dos trabalhos sobre o lazer das mulheres. No ano de 2010 a revista publicou 34 artigos, e apenas 2 deles eram sobre o lazer das mulheres, já no ano de 2020, foram publicados 95 trabalhos, e apenas 5 falavam sobre as mulheres.

É fato que antes de 2010 não houve ocorrências selecionadas para essa análise, e a partir desse ano, parece iniciar um interesse pelo assunto, porém, mesmo sendo um 
tema tão caro para a sociedade, ainda é escasso, principalmente se comparado a outros estudos.

Gráfico 1: Quantidade total de artigos por ano x Quantidade de artigos sobre lazer das mulheres que foram selecionados na revista Licere.

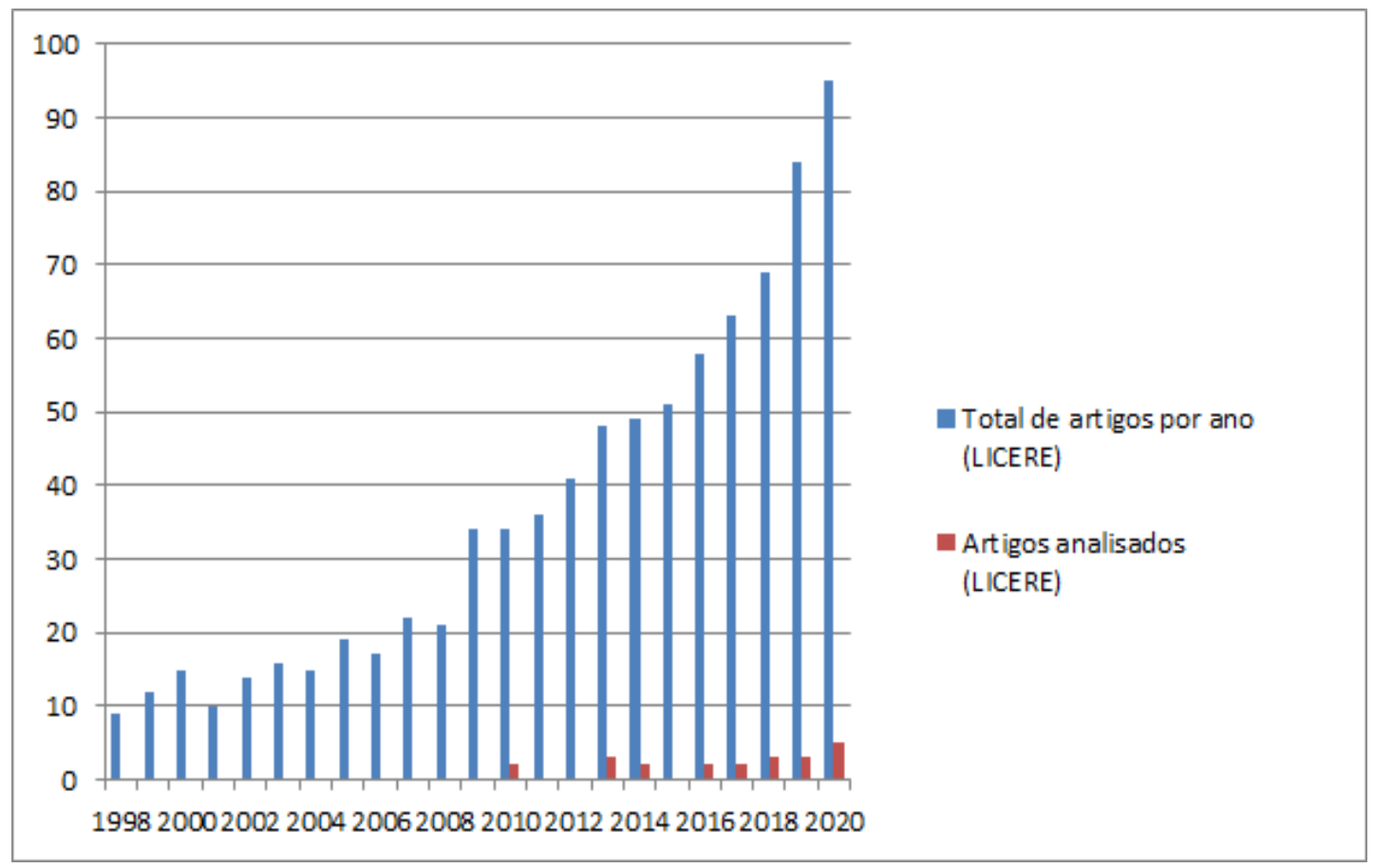

Fonte: Elaborado pelas autoras a partir dos dados da revista.

Gráfico 2: Quantidade total de artigos por ano x Quantidade de artigos sobre lazer das mulheres que foram selecionados na revista RBEL.

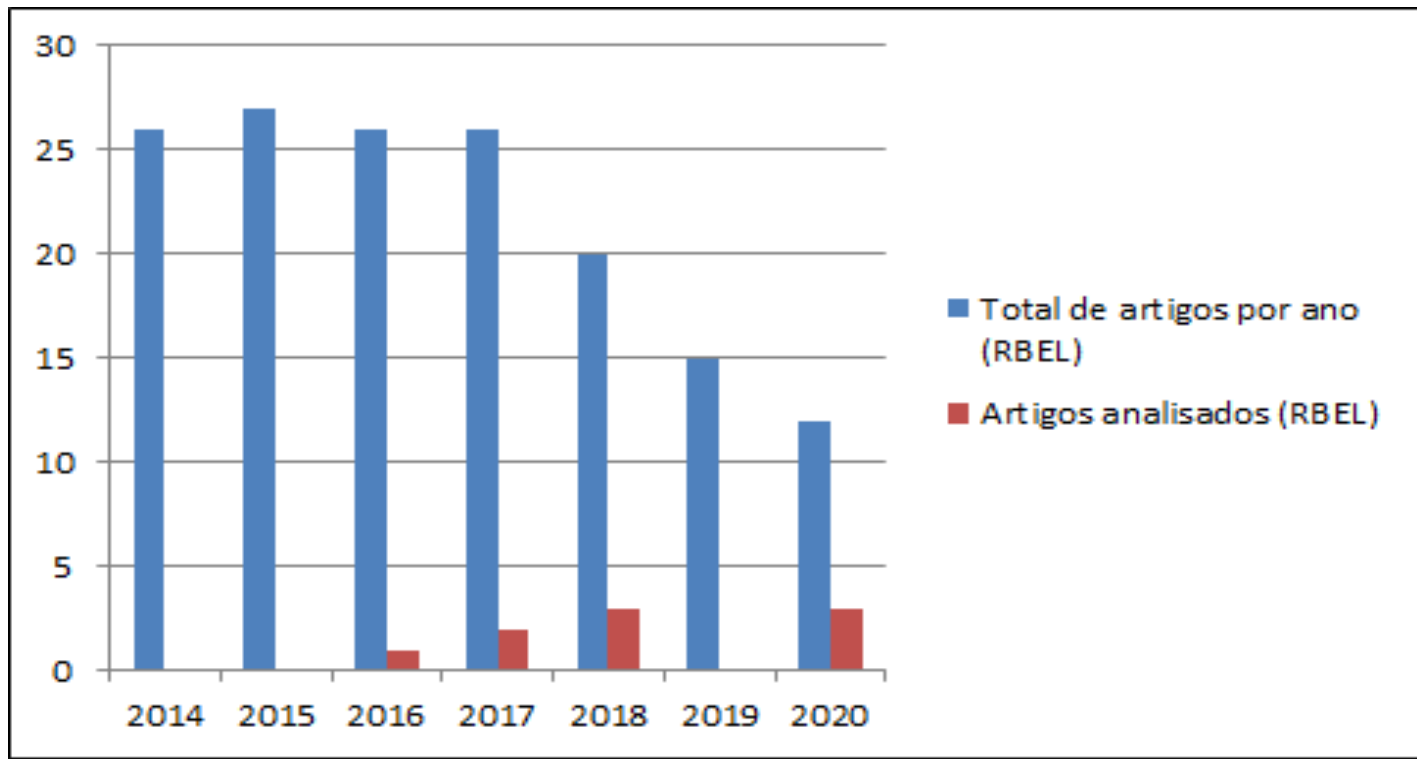

Fonte: elaborada pelas autoras a partir dos dados da revista. 
Outra constatação é que ao menos a metade desses artigos, mesmo tratando de grupos de mulheres ou de análises sobre a mulher, não tensionam a interseccionalidade para tentar trazer essa pauta à tona, em uma tentativa de mudar o cenário feminista que ainda é predominantemente liberal, comandado por ideias de mulheres brancas, que gozam de alguma estabilidade financeira, moradoras de bairros centrais e com possibilidade maior de voz do que outras. Esse é claramente um cenário que precisa ser superado, não que o que estamos propondo é invalidar a voz de alguém, mas escutar a voz de todas e assim, articular um movimento que não seja excludente.

\section{Considerações Finais}

Com a agudização das relações capitalistas, e a consequente crise da reprodução social, alguns grupos sociais e movimentos ganham destaque no cenário político. Esse é o caso das mulheres nesta última década. Movimentos como A primavera árabe (20102012), o Occupy Wall Street (2011), o Ni Una Menos (2015) e o Ele não (2018) contaram com o protagonismo feminino e de suas pautas. Os atos, voltados ao direito ao corpo, sexualidade, luta contra o feminicídio, luta pela legalização do aborto, continuam ocorrendo, e na Argentina, nesse fim de 2020, alçou sucesso a luta pela descriminalização do aborto. No Brasil, os atos do 8 de março têm se tornado cada vez mais massivos nos últimos anos e se colocado como contraponto necessário ao avanço das forças conservadoras, como as narrativas fundamentalistas neopentecostais e obscurantistas que por ora dominam a agenda política. Assim, o estudo acadêmico e as discussões a respeito desses assuntos mostram-se urgentes e necessárias para o aprofundamento, crescimento e conscientização da sociedade.

Dessa forma, o presente estudo pretendeu investigar as publicações de artigos em dois periódicos brasileiros relevantes para o campo dos estudos do lazer. 
Compreendendo como as mulheres ainda vivem em um sistema de desigualdade causada por seu gênero e considerando as implicações que isso ocasiona, este trabalho identificou as fragilidades que ainda existem no campo a respeito das pesquisas sobre mulheres e gênero, a partir de um método quantitativo-qualitativo. Foi possível concluir que apesar do leve crescimento, ainda existem lacunas consideráveis e muito por fazer.

É importante considerar o protagonismo feminino nos estudos encontrados, uma vez que, na Revista Licere, dos 60 autores e autoras responsáveis por esses artigos, a maioria, 38, são mulheres, e na RBEL, são 13 autoras e 6 autores. Isso mostra o interesse das mulheres em visibilizar os estudos de gênero e levantar discussões a respeito, além da presença delas nas pesquisas da área.

Importante frisar que os estudos das mulheres no lazer precisam crescer para abarcar o máximo de experiências e vivências desse grupo, e sempre levando em consideração as classes subalternas, etnias, gênero, entre outras, que podem atravessar as vivências dessa população.

Estudos mais específicos, de mulheres de determinado clube ou bairro, são interessantes para entender as especificidades e as nuances de cada experiência de lazer, porém, acreditamos que é importante que existam pesquisas sobre o lazer das mulheres em contextos mais amplos, para que possamos enxergar melhor a totalidade, e que essas pesquisas discutam mais as questões de classe e raça. Diante disso, convidamos todas e todos a discutirem ao máximo essas questões no ambiente acadêmico e nas ruas, dialogando e problematizando a interseccionalidade que atravessa essas mulheres, podendo ser elas negras, pobres, periféricas, indígenas, LGBTQ+, dentre outras. Somente assim, conseguiremos uma compreensão concreta do patriarcado e do capitalismo que possa nos organizar para enfim mudar o cenário opressor que ainda se faz presente. 


\section{REFERÊNCIAS}

ALMEIDA, M. B., GUTIERREZ D. M., \& OLIVEIRA, A. Corpo e feminilidade a partir da experiência das jogadoras de rugby brasileiras. Revista brasileira de estudos do lazer, v. 4, n. 3, p. 139-153, 2017.

ALVES, Branca Moreira; PITANGUY, Jacqueline. O que é FEMINISMO. 2. ed. São Paulo: Brasiliense, v. 79, 1982.

ARRUZA, C.; BHATTACHARYA, T.; FRASER, N. Feminismo para os 99\%: um manifesto. São Paulo: Boitempo, 2019.

BARBOSA, C.; LIECHTY, T.; PEDERCINI, R. Restrições ao Lazer Feminino: Particularidades das Experiências de Lazer de Mulheres Homossexuais. Licere, v. 16, n. 2, 2013. DOI: http://doi.org/10.35699/1981-3171.2013.653.

BATINGA, G. L.; PINTO, M. R. "Lazer?! Para mim?! ..." - Consumo de lazer por mulheres de baixa renda. Revista Brasileira de Estudos do Lazer. Belo Horizonte, v. 6, n.3, p.78-97, set./dez. 2019.

BETTINE, M.; GUTIERREZ, D. M.; OLIVEIRA, A.Corpo e feminilidade a partir da experiência das jogadoras de rugby brasileiras. Revista Brasileira de Estudos do Lazer. Belo Horizonte, v. 4, n. 3, p. 139-153, set./dez. 2017.

BONALUME, C. R; ISAYAMA, H. F. As mulheres na pesquisa O lazer do brasileiro. Revista Brasileira de Estudos do Lazer. Belo Horizonte, v. 5, n.1, p.3-24, jan./abr. 2018.

O Lazer nas Conferências e nos Planos Nacionais de Políticas para as Mulheres. Licere, [S. 1.], v. 23, n. 2, p. 19-57, 2020. DOI: http://doi.org/10.35699/2447-6218.2020.21783.

BRASIL. Constituição da República Federativa do Brasil. Brasília, DF: Senado Federal, 1988.

BUTLER, J. Gender trouble. Feminism and the subversion of identity. New York: Routledge, 1990.

CAETANO, I. F. O feminismo brasileiro: Uma análise a partir das três ondas do movimento feminismo e a perspectiva da interseccionalidade. EMERJ. 2017.

CAVAlCANTI, T. de S.; MÉLO, R. de S.; SANTOS, A. B. L.; MOURA, C. B. G.; MOURA, D. L. Empoderamento, Mulheres e Práticas Corporais: Uma Revisão Sistemática da Literatura. Licere, v. 21, n. 3, p. 319-344, 2018. DOI: http://doi.org/10.35699/1981-3171.2018.1860.

CHAN-VIANNA, A. J.; MOURA, D. L. Futebol, Mulheres e Interação Social. Licere, v. 20, n. 4, p. 1-21, 2017. DOI: http://doi.org/10.35699/1981-3171.2017.1722. 
CHAVES, E. Dança para Educar e Entreter, o Curso Natália Lessa em Belo Horizonte (1928-1960). Licere, v. 19, n. 2, p. 111-135, 2016. DOI: https://doi.org/10.35699/1981-3171.2016.1238

CRENSHAW, K. W. Mapping the margins: Intersectionality, identity politics, and violence against women of color. Stan. L. Rev., v. 43, p. 1241, 1994.

DAVIS, A. Mulheres, raça e classe. Boitempo, São Paulo, 2016.

DUMAZEDIER, J. Sociologia empírica do lazer. São Paulo: Perspectiva: SESC, 1973.

FLAX, Jane. Pós-modernismo e as relações de gênero na teoria feminista. In: HOLANDA, Heloisa (org.). Pós-modernismo e política. Rio de Janeiro: Rocco, 1991.

FLORENTINO, I. M.; CAMARGO, M. J. G. Atividades de lazer no contexto hospitalar: uma estratégia de humanização. Revista Brasileira de Estudos do Lazer. Belo Horizonte, v.2, n.2, p.99-114, mai./ago, 2015.

FORTES, R. Surfe Feminino, Indústria do Surfwear e Promoção da África do Sul: Uma Análise de A Onda dos Sonhos 2. Licere, v. 17, n. 2, p. 283-311, 2014. DOI: http://doi.org/10.35699/1981-3171.2014.857.

FREIRE, I. de A.; CÁRDENAS, R. N.; SÁ, R. de L. A. dos R. M.; SOUZA, E. P. dos S.; TRISTÃO, P. L. Manifestação de Lazer na História de Vida de Idosas do Grupo Pioneiras de Rondônia: Práticas de Lazer na Fase Adulta. Licere, v. 21, n. 2, p. 186225, 2018. DOI: http://doi.org/10.35699/1981-3171.2018.1815.

GOELLNER, S. V.; VOTRE, S. J.; MOURÃO, L.; FIGUEIRA, M. L. M. Lazer e Gênero nos Programas de Esporte e Lazer das Cidades. Licere, v. 13, n. 2, 2010. DOI: https://doi.org/10.35699/1981-3171.2010.815

GOMES, C. L.; MAIA, M. F. Q. C.; SILVA, M. R. C. F.; GONTIJO, R. O cinema como experiência de lazer e as personagens femininas do filme "Para Minha Amada Morta". Revista Brasileira de Estudos do Lazer. Belo Horizonte, v. 3, n. 2, p.3-19, mai./ago. 2016.

Lazer: Necessidade humana e dimensão da cultura. Revista Brasileira de Estudos do Lazer, Belo Horizonte, v. 1, n. 1, p. 3-20, 2014.

Lazer e cinema: representações das mulheres em filmes latino-americanos contemporâneos. Licere (Online), v. 19, n. 4, 2016. DOI: http://doi.org/10.35699/19813171.2016.20042.

Lazer e Cinema: Simbolismos e Representações de Gênero no Filme "Boi Neon". Licere, v. 22, n. 2, p. 193-217, 2019. DOI: http://doi.org/10.35699/19813171.2019 .13554 .

HOBSBAWM, E. J. A era dos extremos: o breve século XX: 1914-1991. São Paulo: Companhia das Letras, 1994. 
LAURENTIS, T. de. A tecnologia do gênero. In: HOLLANDA, Heloísa Buarque de (org.). Tendências e impasses: o feminismo como crítica da cultura. Rio de Janeiro: Rocco, 1987.

MACLURE, K., PAUDYAL, V., STEWART, D. Reviewing the literature, how systematic is systematic? Int J Clin Pharm. March 2016.

MARCELLINO, N. C. Educação e lazer. São Paulo: Moderna, 1987.

O lazer na atualidade brasileira-perspectivas na formação, atuação profissional. Licere. v. 3, n. 1, 2000.

MAYOR, S. T. S. et al. Barreiras de Acesso ao Lazer das Mulheres Segundo Raça/Cor e Classe Social nas Regiões Sudeste e Nordeste do Brasil. Revista Brasileira de Estudos do Lazer, v. 7, n. 2, p. 1-22, 2020.

MAZO, J. Z.; SILVA, C. F. da; LYRA, V. B. As Mulheres no Cenário do Associativismo Esportivo em Porto Alegre/RS na Transição do Século XIX para o XX: Alternativas de Sociabilidade e Lazer para Elas. Licere, v. 13, n. 3, 2010. DOI: http://doi.org/10.35699/1981-3171.2010.798.

MEIRA, J. C. Estudos de Gênero e Historicidade: Sobre a construção cultural das diferenças. Caderno Espaço Feminino, v. 27, n. 2, 2014.

MELO, V. A. Lazer e minorias sociais. São Paulo: IBRASA, 2003. ; DRUMMOND, E. Introdução ao lazer, Rio de Janeiro: Manole, 2003.

MENDES, L. V. C.; ALVES, C. Currículos e Resistências: Libertem Ângela Davis e Todos os Presos Políticos. Licere, v. 22, n. 2, p. 375-398, 2019. DOI: http://doi.org/10.35699/1981-3171.2019.13572.

MINAYO, M. C. S; SANCHES, O. Quantitativo-qualitativo: oposição ou complementaridade? Cadernos de Saúde Pública, Rio de Janeiro, v. 9, n. 3, p. 239262, jul./sep., 1993.

MUNNÉ, F. Ócio y tiempo libre: consideraciones desde una perspectiva crítica. Licere, Belo Horizonte, v. 5, n. 1, p. 59-72, 2002.

NASCIMENTO, D. P. do, SALDANHA, R. M., e FIDALGO, M. Lazer e Urbanização Na Contemporaneidade: Entre o Direito e a Mercadorização. Licere, v. 22, n. 4, p. 656679, 2019. DOI: https://doi.org/10.35699/1981-3171.2019.16284.

OLIVEIRA, A. Feminismo. Enciclopédia Luso-Brasileira. Lisboa, 1969.

PEREIRA NETO, G. P.; ABREU, E. S. de; NASCIMENTO, J. de F.; OLIVEIRA, B. N. de; MACHADO, A. A. N. Surfe é Estilo de Vida : Motivação Para a Prática em Mulheres Jovens. Licere, v. 20, n. 1, p. 115-139, 2017. DOI: http://doi.org/10.35699/1981-3171.2017.1589. 
POLO, M. C. E; TAVARES, G. H. Políticas públicas de financiamento de pesquisas: a participação das mulheres no âmbito dos Estudos do Lazer e do Esporte. Revista Brasileira de Estudos do Lazer, Belo Horizonte, v. 6, n.2, p.56-71, mai./ago. 2019.

RICARDO, L. I. C.; RIBEIRO, J. A. B.; FERREIRA, R. W.; CAVALLI, A. S. Preferências de Atividades de Lazer de um Grupo de Idosas do Extremo Sul do Brasil. Licere, v. 16, n. 2, 2013. DOI: http://doi.org/10.35699/1981-3171.2013.648.

SANTOS, A. B. L.; CAVAlCANTI, T. de S.; MOURA, C. B. G.; MOURA, D. L. Valeu o Boi! Uma Análise de Gênero Sobre a Prática de Mulheres na Vaquejada. Licere, v. 23, n. 1, p. 92-111, 2020. DOI: http://doi.org/10.35699/19813171.2020.19688.

SANTOS, L. F. A. Apostila Metodologia da Pesquisa Científica II. Faculdade Metodista de Itapeva. 2006.

SCOTT, Joan. "Gender: A Useful Category of Historical Analysis". Gender and the Politics of History. New York: Columbia University Press, 1989.

SilvA, B. B. F.; SILVA, A. A. da; MELO, G. F. de; CHARIGLIONE, I. P. F. S. Avaliação dos Estados de Humor e Qualidade de Vida de Idosas em Diferentes Contextos de Vida e a Percepção da Importância do Lazer. Licere, v. 22, n. 1, p. 24-48, 2019. DOI: http://doi.org/10.35699/1981-3171.2019.12310.

SILVA, C. L. da; CEZARINO, M.; CARVAlHO, L. de A.; SOUZA, M. F. de. Experiências Pedagógicas a Partir de Histórias em Quadrinhos de Super-Heróis: Educação para o Lazer. Licere, v. 21, n. 2, p. 96-135, 2018. DOI: http://doi.org/10.35699/1981-3171.2018.1812.

SILVA, I. M.; ROSA, M. C. Da Participação de Mulheres no Futebol em Barbacena/MG nas Três Primeiras Décadas do Século XX. Licere, v. 23, n. 2, p. 112 140, 2020. DOI: http://doi.org/10.35699/2447-6218.2020.24004.

SILVA, S. V.. Os Estudos de gênero no Brasil: Algumas considerações. Revista Bibliográfica de Geografía y Ciencias Sociales. Universidad de Barcelona, n. 262, 2000 .

SOUSA, Eustáquia Salvadora de. Meninos, à marcha! Meninas à sombra: a história do ensino da Educação Física em Belo Horizonte (1897-1994). 1994. Tese (Doutorado). Universidade Estadual de Campinas, Campinas, 1994.

SOUTTO MAYOR, S. T.; SILVA, M. de S.; LOPES, C. G. Perspectivas sobre o Lazer das Mulheres com a Pandemia do Novo Coronavírus: Reflexões a partir dos Dados da Pesquisa "O Lazer no Brasil - Representações e Concretizações das Vivências Cotidianas". Licere, v. 23, n. 3, p. 163-189, 2020. DOI: http://doi.org/10.35699/24476218.2020.25363.

SOUZA NETO, G. J. de; CAMPOS, P. A. F.; SILVA, S. R. da. Das Senhoras e Senhorinhas nos "Grounds" do Sport Bretão: A História da Mulher nos Campos de Futebol em Belo Horizonte/MG (1904 -1920). Licere, v. 16, n. 3, 2013. DOI: http://doi.org/10.35699/1981-3171.2013.636. 
TEJERA, D. B. O.; SOUSA, I. R. C. de; SAMPAIO, T. M. V. As Relações de Gênero na Opção de Lazer de Pessoas Atuantes em Cooperativas de Trabalho. Licere, v. 16, n. 4, 2013. DOI: http://doi.org/10.35699/1981-3171.2013.668

VIANA, I. P. Território Funk e Feminilidades: subjetividades construídas entre relações de poder, a rua e a violência. Revista Brasileira de Estudos do Lazer, Belo Horizonte, v. 3, n.3, p.118-135, set./dez. 2016.

WEDIG, J. C.; WAllaU, A. S. de; PADIlHA, A. F.; SIMONETTI, A. L. Sociabilidade e Lazer entre Mulheres Camponesas: Vivências no Clube de Mães. Licere, v. 23, n. 2, p. 58-81, 2020. DOI: https://doi.org/10.35699/24476218.2020.21784

\section{Endereço das Autoras:}

Julia Drumond Cunha

Rua Afonso Ferreira Gomes, 83 - Castelo

Belo Horizonte - MG - 31.330-400

Endereço Eletrônico: juliadrumondcunha@gmail.com

Verônica Toledo Ferreira de Carvalho

Rua Engenheiro Oscar Ferreira, 329, apto. 801

Recife - PE - 52.051-432

Endereço eletrônico: veronica.usa24@gmail.com 